\author{
Innocenzo Rainero \\ Edvige Fasano \\ Elisa Rubino \\ Chiara Rivoiro \\ Walter Valfrè \\ Salvatore Gallone \\ Lidia Savi \\ Salvatore Gentile \\ Rossana Lo Giudice \\ Paola De Martino \\ Anna Maria Dall'Omo \\ Lorenzo Pinessi
}

Published online: 20 July 2005

I. Rainero (西) • E. Rubino • C. Rivoiro W. Valfrè • S. Gallone • L. Savi • S. Gentile R. Lo Giudice • P. De Martino • L. Pinessi Neurology III, Headache Center,

Department of Neuroscience, University of Turin, Via Cherasco 15, I-10126 Turin, Italy

e-mail: irainero@molinette.piemonte.it

Tel.: +39-011-6638510

Fax: +39-011-6963487

E. Fasano • A.M. Dall'Omo

Transplantation Immunology,

San Giovanni Battista Hospital of Turin,

Turin, Italy

\section{Association between migraine and HLA-DRB1 gene polymorphisms}

ent alleles of the HLA-DRB1 locus. Our data suggest the presence of a genetic susceptibility factor for migraine within the HLA region.
Key words HLA-DRB1 • Migraine • Aura $\cdot$ Major histocompatibility complex $\cdot$ MHC

\section{Introduction}

Migraine is a chronic neurovascular disorder that, in Western countries, affects approximately $15 \%$ of the general population [1]. The aetiology of migraine is still unknown but several studies support a strong genetic basis for the disease [2]. Mutations in the CACNAIA and ATPIA2 genes are associated with familial hemiplegic migraine, a rare subtype of migraine with aura $[3,4]$. The genes involved in the more common form of migraine, like migraine with and without aura, are still unknown.

Epidemiological studies have shown the presence of a significant comorbidity between migraine and some diseases related to the HLA system, like asthma and narcolepsy $[5,6]$. This comorbidity suggests the presence, within the HLA region, of genetic factors involved in the disease pathogenesis.

Previous studies evaluating the relation between HLA system and migraine provided conflicting results [7, 8]. Recently, a significant association was found between migraine and polymorphisms of two genes, TNF-alpha and TNF-beta, located in the HLA Class III region [9, 10].

To further investigate this issue, we performed an association study between polymorphisms of the HLA-DRBI gene and migraine in a large cohort of Italian migraine patients. The purpose of this study was to assess whether $H L A-D R B 1$ alleles confer susceptibility to migraine or are related to specific clinical subgroups. 


\section{Materials and methods}

Two hundred and fifty-five consecutive migraine patients ( 77 males, 178 women; mean age $\pm \mathrm{SD}=40.87 \pm 13.10$ years) attending the Headache Center of the University of Turin (Italy), were involved in the study. The diagnosis of migraine was made according to the International Classification of Headache Disorders (ICHD-II) criteria [11]. For additional analyses, migraine patients were divided into 2 subgroups: (A) migraine without aura (ICHD-II code 1.1), 214 patients (65 males, 149 females; mean age $\pm \mathrm{SD}=41.5 \pm 12.0$ years); and (B) migraine with aura (ICHD-II code 1.2), 41 patients (12 males, 29 females; mean age $\pm \mathrm{SD}=36.4 \pm 13.6$ years). A group of 325 age and geographically matched healthy subjects (151 males, 174 females, mean age $\pm \mathrm{SD}=41.96 \pm 14.86$ years) served as control. The controls were blood donors and were screened by a neurologist specialised in headaches in order to exclude migraine and/or cluster headache. The protocol of this study was reviewed and approved by the Medical Ethics Committee of the San Giovanni Battista Hospital of Turin and written informed consent was obtained from all participants.

Genomic DNA was extracted from EDTA-treated blood using a commercial DNA extraction kit (QiAmp blood kit; Kagan, Crawley, UK). HLA-DRB1 typing was performed at the two-digit level by PCR amplification using specific probes and primers (Dynal Biotech Ltd., Bromborough, Wirral, UK). The Hardy-Weinberg equilibrium was verified for all tested populations. Statistical analyses were performed using SigmaStat version 1.0 (Jandel Corp., 1994, San Rafael, CA). A level of $p<0.05$ was accepted as statistically significant.

\section{Results}

Table 1 shows the distribution of $H L A-D R B 1$ alleles in migraine patients and controls. The phenotypic frequencies of $H L A-D R B 1$ alleles were similar to those previously found in the Italian population [12]. In patients with migraine, the frequency of the HLA-DRB $1 * 12$ allele was found to be significantly lower than in controls $\left(\chi^{2}=5.03\right.$, $p=0.025$, OR: $0.28,95 \%$ CI: $0.08-0.88)$. The frequency of HLA-DRB $1 * 16$ was significantly higher $\left(\chi^{2}=4.10\right.$, $p=0.043$, OR: $1.80,95 \% \mathrm{CI}: 1.02-3.19)$ in migraine patients. No significant difference was found in the remaining alleles.

Table 2 shows the comparison of HLA-DRB1 alleles between migraine subgroups and healthy controls. In

Table $1 H L A-D R B 1$ allele distribution in migraine patients and controls

\begin{tabular}{|c|c|c|c|c|}
\hline Allele & Migraine patients $(n=255)$ & Healthy controls $(n=325)$ & $p$ & OR $(95 \% \mathrm{CI})$ \\
\hline $\mathrm{DRB} 1 * 01$ & 42 & 58 & 0.74 & \\
\hline $\mathrm{DRB} 1 * 03$ & 38 & 52 & 0.81 & \\
\hline $\mathrm{DRB} 1 * 04$ & 46 & 58 & 0.96 & \\
\hline DRB $1 * 07$ & 52 & 82 & 0.24 & \\
\hline DRB1*08 & 11 & 16 & 0.88 & \\
\hline DRB $1 * 09$ & 1 & 1 & 0.59 & \\
\hline DRB $1 * 10$ & 11 & 5 & 0.08 & \\
\hline $\mathrm{DRB} 1 * 11$ & 136 & 174 & 0.98 & \\
\hline DRB1*12 & 4 & 18 & 0.025 & $0.28(0.08-0.88)$ \\
\hline DRB1*13 & 60 & 73 & 0.85 & \\
\hline DRB $1 * 14$ & 40 & 34 & 0.10 & \\
\hline DRB1*15 & 36 & 55 & 0.39 & \\
\hline $\mathrm{DRB} 1 * 16$ & 33 & 24 & 0.043 & $1.80(1.02-3.19)$ \\
\hline
\end{tabular}

Table 2 Comparison of $H L A-D R B 1$ allele distribution between controls and migraine subgroups

\begin{tabular}{lll}
\hline Allele & Migraine without aura $(n=214)$ & Migraine with aura $(n=41)$ \\
\hline DRB $1 * 01$ & 0.75 & 0.93 \\
DRB $1 * 03$ & 0.84 & 0.99 \\
DRB $1 * 04$ & 0.96 & 0.69 \\
DRB $1 * 07$ & 0.23 & 0.81 \\
DRB $1 * 08$ & 0.66 & 0.78 \\
DRB1 109 & 0.67 & 0.22 \\
DRB1 10 & 0.11 & 0.39 \\
DRB $1 * 11$ & 0.83 & 0.42 \\
DRB $1 * 12$ & 0.06 & 0.25 \\
DRB1 13 & 0.99 & 0.69 \\
DRB1 $1 * 14$ & 0.05 & 0.90 \\
DRB $1 * 15$ & 0.18 & 0.36 \\
DRB $1 * 16$ & $0.02 *$ & 0.77 \\
\hline
\end{tabular}

*OR: 1.97 ; $95 \%$ CI: $1.10<\mathrm{OR}<3.54$ 
migraine without aura patients, the frequency of the $* 16$ allele was significantly $\left(\chi^{2}=5.35, p=0.045\right.$, OR: $1.97,95 \%$ CI: 1.10-3.54) increased in comparison with controls. No significant difference in HLA-DRB1 allele distribution was found in the remaining subgroups.

\section{Discussion}

Our study shows the presence of a significant association between alleles of the $H L A-D R B 1$ gene and migraine. Subjects carrying the $* 12$ allele of this gene present a significant reduction in the risk for migraine, suggesting a protective role for the disease. On the contrary, the carriage of the $* 16$ allele is associated with a two-fold increase in disease risk. When the migraine patients were divided into subgroups (migraine with and without aura), only migraine without aura patients presented a significant increase of the
*16 allele. These alleles may be considered as risk factors for migraine without aura in the Italian population. In a previous study, Martelletti et al. [13] genotyped 45 migraine patients for $H L A-D R B 1$ alleles and found no significant difference with controls. The number of patients examined in this study was probably too low for the detection of a statistically significant difference.

The most likely explanation of our data is that the $D R B 1$ locus is in linkage disequilibrium (LD) with other genetic polymorphisms which are responsible for this association. The DRB1 gene is located on chromosome $6 \mathrm{p} 21$, within the HLA-Class III region, and this region is characterised by a high LD [14]. Further studies, using different methods for HLA analysis, are needed to confirm the presence of susceptibility genes for migraine in this genomic region.

Acknowledgements The study was supported by grants from the Ministero dell'Università e della Ricerca Scientifica (MURST) and from the Regione Piemonte (Italy).

\section{References}

1. Lipton RB, Scher AI, Kolodner K et al (2002) Migraine in the United States: epidemiology and patterns of health care use. Neurology 58:885-894

2. Ducros A, Tournier-Lasserve E, Bousser MG (2002) The genetics of migraine. Lancet Neurol 1:285-293

3. Ophoff RA, Terwindt GM, Vergouwe MN et al (1996) Familial hemiplegic migraine and episodic ataxia type- 2 are caused by mutations in the $\mathrm{Ca}^{2+}$ channel gene CACNL1A4. Cell 87:543-552

4. De Fusco M, Marconi R, Silvestri L et al (2003) Haploinsufficiency of ATP1A2 encoding the $\mathrm{Na}+\mathrm{K}+$ pump alpha2 subunit associated with familial hemiplegic migraine type 2 . Nat Genet 33:192-196

5. Davey G, Sedgwick P, Maier W et al (2002) Association between migraine and asthma: matched case-control study. Br J Gen Pract 52:723-727
6. Dahmen N, Kasten M, Wieczorek S et al (2003) Increased frequency of migraine in narcoleptic patients: a confirmatory study. Cephalalgia 23:14-19

7. Kudrow L (1979) HL-A antigens in cluster headache and classical migraine. Headache 18:167-168

8. Giacovazzo M, Valeri M, Piazza A et al (1987) Elevated frequency of HLA shared-haplotypes in migraine families. Headache 27:575-577

9. Rainero I, Grimaldi LM, Salani G et al (2004) Association between the tumor necrosis factor-alpha $-308 \mathrm{G} / \mathrm{A}$ gene polymorphism and migraine. Neurology 62:141-143

10. Trabace S, Brioli G, Lulli P et al (2002) Tumor necrosis factor gene polymorphism in migraine. Headache 42:341-345
11. Headache Classification Subcommittee of the International Headache Society (2004) The International Classification of Headache Disorders, 2nd edn. Cephalalgia 24[Suppl 1]:1-151

12. Fasano ME, Praticò L, Brancatello $F$ et al (1998) HLA-DRB1 in Caucasian Italian normal. In: Gjertson DW, Terasaki PL (eds) HLA 1998. American Society for Histocompatibility and Immunogenetics, Los Angeles, CA, pp 162-163

13. Martelletti P, Lulli P, Morellini M et al (1999) Chromosome 6p-encoded HLADR2 determination discriminates migraine without aura from migraine with aura. Hum Immunol 60:69-74

14. Stenzel A, Lu T, Koch WA et al (2004) Patterns of linkage disequilibrium in the MHC region on human chromosome 6p. Hum Genet 114:377-385 